\title{
KEMAMPUAN MAHASISWA PGSD DALAM MENGONSTRUKSI PEMAHAMAN KONSEP ALJABAR BERDASARKAN TEORI APOS
}

\author{
Muhammad Ilman Nafi'an $^{1}$, Diesty Hayuhantika $^{2}$, dan Dian Septi Nur Afifah $^{3}$ \\ ${ }^{1}$ Prodi Pendidikan Guru Sekolah Dasar, STKIP PGRI Tulungagung, Indonesia \\ ${ }^{2,3}$ Prodi Pendidikan Matematika, STKIP PGRI Tulungagung, Indonesia
}

\section{Info Artikel}

Sejarah Artikel:

Diterima 3 Agt 2017

Disetujui 19 Okt 2017

Dipublikasikan Des 2017

\section{Keywords:}

student ability,

construction,

understanding

\begin{abstract}
The purpose of this study is to describe the ability of students in constructing the concept of symmetry group. This research was conducted in STKIP PGRI Tulungagung, subjek in this research is PGSD student of Semester VI, Data collection with written test, interviews and documentation. Written tests and interviews were conducted to obtain student data in building understanding of the concept of symmetry group, While documentation is used to record all activities in building understanding of the concept of Symmetry group. The results of this study indicate that At the stage of action the subject is able to show the next steps of showing the permutation link with an equilateral triangle, At the stage of the process is able to show the next steps of imagining the reflection of the triangle, And determine reflection, At the stage of the subject object is confident with the done and able to explain the next steps of imagining the reflection properties of the triangle wake up, and determine the reflection From the nature of the reflection is changed again into a transformation composition, At the subject schema stage can already explain if the triangle is altogether converted into a rectangular or pentagonal wake, then the reflection and composition of its transformation will change, it indicates that the subject already has a scheme about symmetry group.
\end{abstract}

\begin{abstract}
Abstrak
Tujuan penelitian ini adalah untuk mendeskripsikan kemampuan mahasiswa dalam membangun konsep grup simetri dari bangun geometri. Penelitian ini dilaksanakan di stkip pgri Tulungagung, SUbjek dalam penelitian ini adalah mahasiswa PGSD Semester VI, data dikumpulkan dengan teknik tes tertulis, wawancara dan dokumentasi.. Tes tulis dan wawancara dilakukan untuk memperoleh data mahasiswa dalam membangun pemahaman konsep grup Simetri, sedangkan dokumentasi digunakan untuk merekam semua aktifitas dalam membangun pemahaman konsep grup Simetri. Hasil penelitian ini menunjukkan bahwa Pada tahap aksi Subjek mampu menunjukkan langkah-langkah berikutnya yaitu menunjukkan kaitan permutasi tersebut dengan segitiga sama sisi, Pada tahap proses mampu menunjukkan langkah-langkah berikutnya yaitu membayangkan sifat refleksi dari bangun segitiga, dan menetukan refleksi, Pada tahap objek subjek yakin dengan yang dikerjakan dan mampu menjelaskan langkah-langkah berikutnya yaitu membayangkan sifat refleksi dari bangun segitiga, dan menetukan refleksi terhadap sumbu AX, BY dan CZ. Dari sifat refleksi diubah lagi menjadi komposisi transformasi, Dari ketiga tahap tersebut di dapatkan tahap skema yaitu ketiga proses aksi, proses, objek yang saling berkaitan sehingga membentuk skema. pada tahap skema Subjek sudah bisa menjelaskan apabila segitiga sama sisi diubah menjadi bangun segi empat atau segilima, maka refleksi dan komposisi transformasinya akan berubah, hal tersebut menunjukkan bahwa subjek sudah memiliki skema tentang grup simetri
\end{abstract}

(C) 2017 Universitas Muria Kudus
p-ISSN 2087-9385

e-ISSN 2528-696X
Program Studi Pendidikan Guru Sekolah Dasar

Fakultas Keguruan dan Ilmu Pendidikan Universitas Muria Kudus

Kampus UMK Gondangmanis, Bae Kudus Gd. L. 1t I PO. BOX 53

Kudus

Tlp (0291) 438229 ex.147 Fax. (0291) 437198

E-mail: ilman.indonesia@gmail.com 


\section{PENDAHULUAN}

Brown dan Cocking (NCTM, 2000: 20) menyatakan bahwa Pemahaman konseptual merupakan komponen penting dari pengetahuan yang diperlukan untuk mengatasi suatu masalah. Hal ini sejalan dengan pendapat Djaramah (2008: 152) yang menyebutkan bahwa pemahaman konseptual dan pengetahuan prosedural sama pentingnya dalam membangun kecakapan matematika, belajar dengan pemahaman juga membuat pembelajaran berikutnya menjadi lebih mudah.

Berdasarkan observasi dan wawancara di kelas matematika semester V STKIP PGRI Tulungagung ditemukan bahwa pemahaman mahasiswa dalam mempelajari konsep aljabar materi Grup Simetri sudah baik, hal tersebut ditunjukkan dari nilai yang diperoleh rata-rata di atas 70 setelah diadakan post test, tetapi ketika materi grup simetri dikaitkan dengan bangun geometri mahasiswa tampak kesulitan memahami materi tersebut, indikatornya adalah siswa kurang bisa menghubungkan konsep grup simetri dengan rotasi dan refleksi pada gambar geometri, siswa masih belum bisa mengidentifikasi pola yang ada pada perkalian permutasi saat di hubungkan dengan bangun geometri, hal tersebut terjadi karena pemahaman siswa masih rendah.

Ruseffendi (2006:156) bahwa terdapat banyak peserta didik yang setelah belajar matematika, tidak mampu memahami bahkan pada bagian yang paling sederhana sekalipun, banyak konsep yang dipahami secara keliru sehingga matematika dianggap sebagai ilmu yang sulit. Padahal pemahaman konsep merupakan bagian yang paling penting dalam pembelajaran matematika. demikian juga pendapat Zulkardi (2003: 7) bahwa mata pelajaran matematika menekankan pada konsep. Artinya dalam mempelajari matematika peserta didik harus memahami konsep matematika terlebih dahulu agar dapat menyelesaikan soalsoal dan mampu mengaplikasikan pembelajaran tersebut di dunia nyata.

Pada tahun 1976, Richard Skemp mengomunikasikan hasil studinya tentang pemahaman dalam pendidikan matematika. Dalam artikelnya yang terkenal, "Relational and Instrumenal Understanding” (Skemp, 1976), dijelaskan pengkategorian pemahaman dibedakan menjadi dua, yaitu relational understanding (pemahaman relasional) dan Instrumenal Understanding (pemahaman instrumenal). Instrumenal Understanding yaitu pengetahuan tentang sesuatu tanpa mengetahui alasannya mengapa hal itu terjadi dan relational understanding yaitu pengetahuan tentang suatu hal bagaimana dan mengapa hal itu dapat terjadi. Menurut Hiebert, J. \& Carpenter (1992) pemahaman adalah salah satu aspek dalam belajar yang digunakan sebagai dasar mengembangkan model pembelajaran dengan memperhatikan indikator pemahaman. Hiebert membagi pemahaman menjadi dua jenis yaitu; pemahaman prosedural dan pemahaman konseptual, sedangkan Mousley (tt) membedakan pemahaman matematika menjadi tiga kategori umum yang meliputi: (1) pemahaman sebagai kemajuan struktur, (2) pemahaman sebagai bentuk tahu, (3) pemahaman sebagai proses. Pemahaman siswa dapat dilihat dari bagaimana siswa mengetahui masalah, bagaimana siswa melakukan prosesnya dan kemajuan strukurnya.

Byers dan Hercsovics (1977) menganalisis ide Skemp itu dan mengembangkannya lebih jauh. yaitu, siswa terlebih dahulu berada pada pemahaman antara pemahaman intuitif (intuitive understanding) dan pemahaman formal (formal understanding). Pertama, sebelum sampai pada pemahaman instrumenal, siswa terlebih dahulu berada pada pemahaman intuitif. Mereka mendefinisikannya sebagai berikut. "Intuitive understanding is the ability to solve a problem without prior analysis of the problem." Pada tingkat ini siswa sering menebak jawaban berdasarkan pengalamanpengalaman keseharian dan tanpa melakukan analisis terlebih dahulu. Akibatnya, meskipun siswa dapat menjawab suatu pertanyaan dengan benar, tetapi dia tidak dapat menjelaskan kenapa (why). Kedua, sebelum siswa sampai pada pemahaman relasional, biasanya mereka akan melewati pemahaman yang disebut dengan pemahaman formal. Pemahaman formal didefinisikan sebagai berikut," Formal understanding is the ability to connect mathematical simbol ism and notation with relevant mathematical ideas and to combine these ideas into chains of logical reasoning"(Herscovics \& Bargeon, 1983). Pada pemahaman formal siswa mampu menghubungkan simbol -simbol dan notasi matematika dengan ide-ide matematika yang relevan serta menggabungkan ide-ide tersebut ke dalam pemikiran yang logis.

Mrozek (2000) menyatakan pemahaman merupakan suatu proses memahami arti/makna tertentu dan kemampuan menggunakannya konsep pada situasi lain. sependapat dengan itu Kinach (2002) menjelaskan pemahaman merupakan proses yang di dalamnya meliputi (1) pemahaman konten (kemampuan memberikan contoh-contoh yang benar tentang kosa kata (istilah dan notasi), (2) pemahaman konsep 
yaitu kemampuan mengidentifikasi pola, menyusun definisi, mengaitkan konsep yang satu dengan yang lain. Kemudian Watson (2000) siswa dikatakan paham apabila mempunyai Kemampuan untuk melakukan dan menggunakan konsep dan prosedur matematika dan mampu dalam penggunaan matematika dalam konteks tertentu serta menghubungkan antar konsep matematika.

Beberapa penelitian tentang pemahaman yang ada selama ini masih meneliti tentang bagaimana pemahaman yang dimiliki oleh siswa ,dan belum membahas tentang bagaimana proses siswa membangun pemahamanya, diantaranya adalah penelitian Septi (2010) dengan judul pemahaman mahasiswa dalam menyelesaikan masalah matematika ditinjau dari gaya kognitif FI dan FD, dalam penelitian tersebut hanya mengungkap pemahaman relasional dan instrumental dari mahasiswa dengan gaya kognitif FI dan FD, berikutnya penelitian Yayan (2014) analisis kesalahan mahasiswa dalam menyelesaikan soal cerita ditinjau dari pemahaman relasional dan Instrumental, dalam penelitian tersebut hanya di bahas kesalahan siswa dari pemahaman yang dimilikinya, oleh karena itu perlu diteliti bagaimana mahasiswa membangun pemahaman, dalam membangun pemahaman peneliti menggabungkan teori-teori pemahaman berdasarkan teori Mrozek, Kinach dan Watson, karena ketiga teori tersebut memandang pemahaman sebagai proses, sehingga pemahaman dalam penelitian ini indikatornya adalah Proses Menggunakan konsep, Proses menggunakan Prosedur, dan Proses menghubungkan konsep dengan situasi/konsep lain, sehingga tujuan penelitian ini adalah mendeskripsikan kemampuan mahasiswa dalam membangun konsep grup simetri dari bangun geometri.

Menurut Hiebert, J. \& Carpenter (dalam Jung, 2002) pemahaman adalah salah satu aspek dalam belajar yang digunakan sebagai dasar mengembangkan model pembelajaran dengan memperhatikan indikator pemahaman. Hiebert membagi pemahaman menjadi dua jenis yaitu; pemahaman prosedural dan pemahaman konseptual, sedangkan Mousley (tt) membedakan pemahaman matematika menjadi tiga kategori umum yang meliputi: (1) pemahaman sebagai kemajuan struktur, (2) pemahaman sebagai bentuk tahu, (3) pemahaman sebagai proses. Pemahaman siswa dapat dilihat dari bagaimana siswa mengetahui masalah, bagaimana siswa melakukan prosesnya dan kemajuan strukurnya. Piaget (dalam Mousley,tt) menggambarkan pemahaman merupakan kemampuan untuk memiliki beberapa hubungan dalam pikiran dan memungkinkan selanjutnya untuk abstraksi. Dalam hal ini siswa dikatakan memahami sesuatu jika mampu menghubungkan ide-ide dalam pikiran dan memungkinkan untuk melakukan abstraksi untuk langkah selanjutnya. Pemahaman sebagai proses organisasi dan menekankan bahwa aktivitas kognitif bertujuan untuk memecahkan masalah, Von Glasersfeld (dalam Mousley, $\mathrm{tt}$ ).

Hudojo (1998: 111) mengatakan bahwa pemahaman konsep dapat dicek apakah siswa itu mampu memberikan sendiri contoh-contoh atau tidak. Sedangkan pendapat Johnson-Laird (dalam Marpaung, 1999) menyatakan bahwa pengetahuan dapat dibedakan menjadi tiga jenis: (a) pengetahuan tentang pengertian sebagai kemampuan untuk mengenal dan mewujudkan kembali petunjuk, lambang dan definisi, (b) pengetahuan tentang cara pengungkapan matematika dalam arti yang umum, (c) pengetahuan tentang cara kerja sebagai kemmapuan untuk mewujudkan kembali algoritma matematika dan proses pemecahan soal secara skematis yang lain. Purwanto, 2004 mengemukakan bahwa pemahaman adalah tingkat kemampuan yang menuntut siswa mampu memahami arti atau konsep, situasi serta fakta yang diketahui.

Mrozek (2000) menyatakan pemahaman merupakan suatu proses memahami arti/makna tertentu dan kemampuan menggunakannya konsep pada situasi lain. sependapat dengan itu Kinach (2002) menjelaskan pemahaman merupakan proses yang di dalamnya meliputi (1) pemahaman konten (kemampuan memberikan contoh-contoh yang benar tentang kosa kata (istilah dan notasi), (2) pemahaman konsep yaitu kemampuan mengidentifikasi pola, menyusun definisi, mengaitkan konsep yang satu dengan yang lain. Kemudian Watson (2000) siswa dikatakan paham apabila mempunyai Kemampuan untuk melakukan dan menggunakan konsep dan prosedur matematika dan mampu dalam penggunaan matematika dalam konteks tertentu serta menghubungkan antar konsep matematika. dalam penelitian ini peneliti menggabungkan teori-teori pemahaman berdasarkan teori Mrozek, Kinach dan Watson, karena ketiga teori tersebut memandang pemahaman sebagai proses, sedangkan Pemahaman terhadap suatu konsep matematika merupakan hasil konstruksi atau rekonstruksi terhadap objek-objek matematika. Konstruksi atau rekonstruksi tersebut dilakukan melalui aktivitas berupa aksi-aksi matematika, prosesproses, objek-objek yang diorganisasikan dalam suatu skema untuk memecahkan suatu permasalahan (Dubinsky, 2000; DeVries, 2001). 
Hal ini dapat dianalisis melalui suatu analisis dekomposisi genetik sebagai operasionalisasi dari teori APOS (Action, Prosesses, Object, and Schema). Dalam penelitian ini teori pemahaman yang digunakan adalah teori APOS.

\section{METODE PENELITIAN}

Penelitian ini dilaksanakan di STKIP PGRI Tulungagung, subjek dari penelitian ini adalah mahasiswa semester VI alasan memilih subjek semester VI karena terdapat mahasiswa yang mengikuti mata kuliah aljabar dan banyak mahasiswa yang pemahamanya masih rendah mengenai mata kuliah aljabar khususnya grup simetri dari bangun geometri. dalam satu kelas di ambil minimal satu mahasiswa dan diberikan tes untuk mengetahui mahasasiswa dalam membangun pemahaman matematika kemudian di tindak lanjuti dengan wawancara untuk mendapatkan informasi yang lebih dalam.

Dalam penelitian ini yang menjadi instrumen utama adalah peneliti sendiri, artinya kedudukan peneliti merupakan penentu dalam menyaring data. Oleh karena itu pada saat pengumpulan data di lapangan, peneliti berperan serta selama proses penelitian dan mengikuti secara aktif kegiatan subjek penelitian yang berhubungan dengan pengumpulan data yang dilakukan melalui tes dan wawancara.

Teknik Pengumpulan data dalam penelitian ini dilakukan dengan tes tulis, wawancara dan dokumentasi, dilakukan untuk memperoleh data mahasiswa dalam membangun pemahaman konsep grup Simetri. Setelah itu dilakukan tes tulis dan wawancara dilakukan untuk memperoleh data mahasiswa dalam membangun pemahaman konsep grup Simetri Sedangkan dokumentasi digunakan untuk merekam semua data dalam membangun pemahaman konsep grup Simetri.

Untuk menguji keabsahan data dalam penelitian ini dilakukan triangulasi. Triangulasi yang digunakan dalam penelitian ini adalah triangulasi metode. Dalam pengumpulan data, peneliti memberikan tes pertama tertulis kepada subjek peneliti. Setelah memberikan tes, peneliti melakukan wawancara terhadap permasalahan yang telah dikerjakan. Proses tersebut menghasilkan data berupa jawaban tertulis dan lisan berupa rekaman. Untuk memeriksa keabsahan data maka peneliti melakukan triangulasi dengan melihat kecocokan hasil tes tulis dan wawancara.

\section{HASIL DAN PEMBAHASAN}

Soal matematika yang digunakan dalam penelitian ini terdiri dari satu soal. Konsep materi matematika yang digunakan adalah materi Grup
Permutasi yang sedang dipelajari oleh mahasiswa semester V. Dalam penelitian ini diambil satu subjek untuk dianalisis, yaitu subjek RW. Pada tahap aksi mahasiswa RW berusaha mengaitkan permutasi tersebut dengan tiga simbol pada titik a,b,c berturut-turut nomor 1,2 , 3 , namun belum diketahui maksud mengaitkan dengan tiga simbol tersebut sehingga dilakukan wawancara yang hasilnya sebagai berikut:

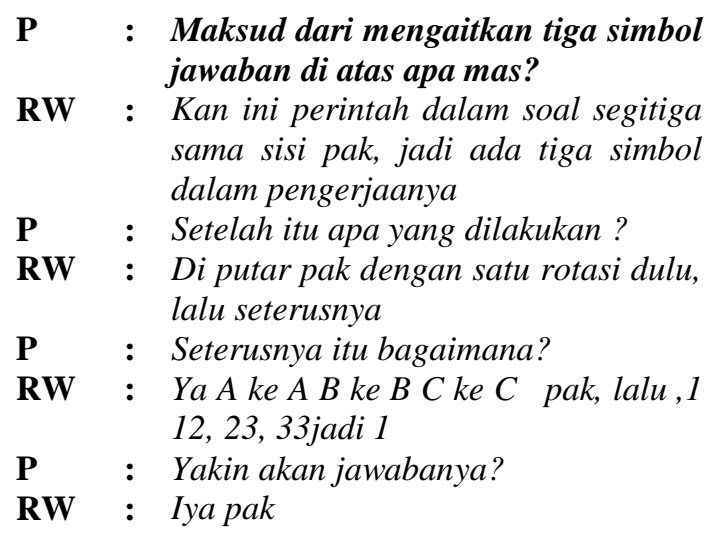

Subjek berusaha mengaitkan permutasi tersebut dengan tiga simbol pada titik a,b,c berturut-turut nomer 1, 2 ,3.untuk menentukan I. Pada tahap aksi subjek RW yakin dengan yang dikerjakan dan mampu menunjukkan langkahlangkah berikutnya yaitu menunjukkan kaitan permutasi tersebut dengan segitiga sama sisi.

Pada tahap proses mahasiswa RW berusaha mengaitkan permutasi tersebut dengan tiga simbol pada titik a,b,c berturut-turut nomer 1, 2 ,3setelah itu subjek RW berusaha membayangkan dan menghbungkan dengan refeleksi dai bangun segitiga terhada $\mathrm{p}$ sumbu AX . A direfleksikan terhadap sumbu AX sehingga posisinya menjadi AA, BC, CB. Sehingga 11, 32,23 jadi A namun lebih jelasnya belum akan digali dengan wawancara sebagai berikut :

$$
\begin{aligned}
& \mathbf{P} \quad \text { : Selanjutnya bagaimana mas? } \\
& \text { RW : Saya refleksikan pak? } \\
& \text { P : Refleksi bagaimana mas? } \\
& \text { RW : Ya A, B dan C, kalau saya }
\end{aligned}
$$

Subjek RW berusaha mengaitkan permutasi tersebut dengan tiga simbol pada titik a,b,c berturut-turut nomer 1, 2 ,3.untuk menentukan I kemudian membayangkan sikap refleksi dari bangun segitiga, dan menetukn refleksi terhadap sumbu AX, BY dan CZ. Pada tahap proses subjek RW yakin dengan yang 
dikerjakan dan mampu menunjukkan langkahlangkah berikutnya yaitu membayangkan sifat refleksi dari bangun segitiga, dan menetukn refleksi terhadap sumbu AX, BY dan $\mathrm{CZ}$

Pada tahap objek mahasiswa RW sudah bisa menjelaskan komposisi transformasi, yaitu $\mathrm{RR}=\mathrm{I}, \mathrm{AC}=\mathrm{R}, \mathrm{AR}=\mathrm{B}, \mathrm{RA}=\mathrm{C}, \mathrm{RB}=\mathrm{A}, \mathrm{RC}$ $=\mathrm{B}$. Untuk lebih jelasnya dilakukan wawancara sebagai berikut:

\section{P : Apa maksudnya $R R=I$ \\ RW : Itu hasil dari pengerjaan di atas pak, sehingga membentuk komposisi transformasi dari $R R=i$, $A C=R, \quad A R \quad=B \quad$ dst.sehingga hasilnya nampak}

Pada tahap objek subjek RW yakin dengan yang dikerjakan dan mampu menjelaskan langkah-langkah berikutnya yaitu membayangkan sifat refleksi dari bangun segitiga, dan menetukn refleksi terhadap sumbu AX, BY dan CZ. Dari sifat refleksi diubah lagi menjadi komposisi transformasi.

Dari ketiga tahap tersebut di dapatkan tahap skema yaitu ketiga proses aksi, proses, objek yang saling berkaitan sehingga membentuk skema. Subjek RW sudah bisa menjelaskan apabila segitiga sama sisi diubah menjadi bangun segi empat, maka refleksi dan komposisi transformasinya akan berubah, hal tersebut sesuai dengan wawancara sebagai berikut :

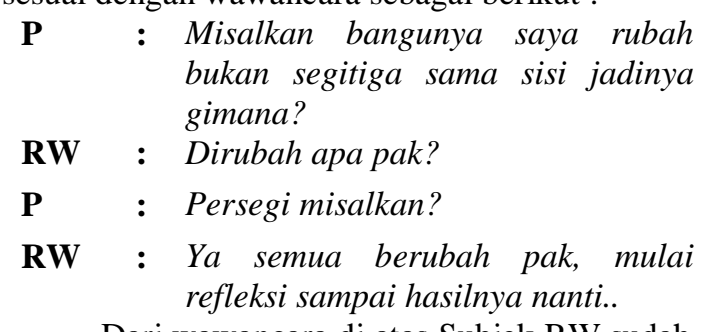

Dari wawancara di atas Subjek RW sudah bisa menjelaskan apabila segitiga sama sisi diubah menjadi bangun segi empat, maka refleksi dan komposisi transformasinya akan berubah. Data pada tahap skema subjek RW sudah bisa menjelaskan apabila segitiga sama sisi diubah menjadi bangun segi empat, maka refleksi dan komposisi transformasinya akan berubah, hal tersebut menunjukkan bahwa subjek RW sudah memiliki skema tentang grup simetri dari bangun geometri.

\section{SIMPULAN}

Pada tahap aksi Subjek mampu menunjukkan langkah-langkah berikutnya yaitu menunjukkan kaitan permutasi tersebut dengan segitiga sama sisi, Pada tahap proses mampu menunjukkan langkah-langkah berikutnya yaitu membayangkan sifat refleksi dari bangun segitiga, dan menetukan refleksi terhadap sumbu AX, BY dan CZ, Pada tahap objek subjek yakin dengan yang dikerjakan dan mampu menjelaskan langkah-langkah berikutnya yaitu membayangkan sifat refleksi dari bangun segitiga, dan menetukan refleksi terhadap sumbu AX, BY dan CZ. Dari sifat refleksi diubah lagi menjadi komposisi transformasi, Dari ketiga tahap tersebut di dapatkan tahap skema yaitu ketiga proses aksi, proses, objek yang saling berkaitan sehingga membentuk skema. pada tahap skema Subjek sudah bisa menjelaskan apabila segitiga sama sisi diubah menjadi bangun segi empat atau segilima, maka refleksi dan komposisi transformasinya akan berubah, hal tersebut menunjukkan bahwa subjek RW dan SY sudah memiliki skema tentang grup simetri dari bangun geometri, sehingga dapat dikatakan bahwa subjek mampu mengonstruksi pemahaman Grup simetri dari bangun geometri.untuk penelitian lanjut sejenis diharapkan dikaitkan dengan interaksi, agar proses konstruksinya jelas, seperti pada penelitian Nafi'an (2017) yang mengatakan siswa perlunya interaksi antara guru dan siswa agar siswa dapat mengkonstruksi pemahaman pada operasi bilangan bulat, selain interaksi baiknya juga dikaitkan dengan gaya kognitif, karena terdapat perbedaan kemampuan dalam menyelesaikan masalah matematika berdasarkan gaya kognitif field Independen (Nafi'an, 2017)

\section{DAFTAR PUSTAKA}

Byers, V and Herscovics, N. 1977. Understanding School Science Mathematic Teaching. 81, 24-27.

Dubinsky, Ed. 2000. Using a Theory of Learning in College Mathematics Course, (Online), http: //www.bham.ac.uk/ctimath/Talum 12. htm or http:/www.telri ac.uk/ (diakses 17 Februari 2004).

Hiebert, J.\& Carpenter P.T. 1992. Learning and Teaching With Understanding..A.Grouws (Ed). Handbook of Research on Mathematics Teaching and Learning.9h.6500) New York: Macmillan Publishing Company.

Hudojo, Herman. 1998. Mengajar Belajar Matematika. Jakarta: Depdikbud Dirjen Dikti.

Syaiful Bahri Djamarah. 2008. Psikologi Belajar. Jakarta: Rineka Cipta. 
Jung, Inchul. 2002. Student Representation and Understanding of Geometric Transformation With Technology Experience. Dissertation. The university of Georgia. Pdf. http://jwilson.coe.uga.edu/pers/jung_inchul _200205_phd.pdf . Diakses 13 Desember 2016.

Kinach, M.B. 2002. Understanding and Learning to Explain by Representing Mathematics : Epistemological Dilemmas Facing Teacher Educators in the Secondary Mathematics "Method" Course Journal of Mathematics Teacher Education,5,153-186.

Marpaung, Y. 1999. Mengejar Ketertinggalan Kita Dalam Pendidikan Matematika Disampaikan Dalam Upacara Pembukaan Program S3 Pendidikan Matematika Universitas Negeri Surabaya.

Mousley, Judith. What Does Mathematics Understanding Look Like?. Deakin University.Pdf.http://www.merga.net.au/do cuments/RP622005.pdf. Diakses 18 Mei 2017.

Mrozek, J. 2000. The Problems of Understanding Mathematics, (Online).

Nafi'an, M.I. 2017. Interaksi Guru SD Untuk Membantu Siswa Mengonstruksi Pemahaman Konsep Matematika, INSPIRASI (JURNAL ILMU SOSIAL). Vol 16, H. 36-42.

Nafi'an, MI. 2017. Bagaimana kemampuan siswa sd dengan gaya kognitif field independen memecahkan masalah matematika? jurnal pena sd vol 1 h.12-24.

National Council of Teachers of Mathematics. 2000. Principles and Standards for School Mathematics. Reston, VA:NCTM.
Ruseffendi, E.T. 2006. Pengantar Kepada Membantu Guru Mengembangkan Kompetensinya dalam Pengajaran Matematikauntuk Meningkatkan CBSA. Bandung: Tarsito

Septi, Dian. 2010. Pemahaman Siswa Sma Ditinjau Berdasarkan Gaya Kognitif, Tesis. Unesa: Tidak dipublikasikan.

Skemp, R. 1976. Relational Understanding and Instructional Understanding Mathematic Teaching. $\quad 77, \quad 20-26$. http://www.grahamtall.co.uk/skemp/pdfs /instrumenal-relational.pdf . Diakses 1 Desember 2015.

Sugiyono. 2008. Metode Penelitian Kunatitatif Kualitatif dan $R \& D$. Bandung Alfabeta.

Sukardi. 2005. Metodologi Penelitian Pendidikan. Jakarta: PT Bumi Aksara.

Djamarah, Syaiful Bahri. 2008. Psikologi Belajar. Jakarta : PT. Rineka Cipta

Wallace, D. A. R. 2004. The algebraic stucture of group rings.,Bulletin of American Mathematical Society vol. 1 No. 2.

Watson, J. M., \& Shaughnessy, J. M. 2004. Proportional reasoning: Lessons from research in data and chance. Mathematics Teaching in the Middle School, 10 , 104109.

Yayan, 2015. Analisis kesalahan Siswa Dalam Menyelesaikan Soal Cerita ditinjau berdasarkan pemahaman relasional dan instrumental. STKIP PGRI Tulungagung.: Tidak dipublikasikan.

Zulkardi. 2003. Realistic Mathematics Education (RME) atau Pendidikan Matematika Realistik Indonesia (PMRI). (makalah: paper disampaikan pada Semiloka Nasional 20-21 Agustus 2003), Palembang. 